\title{
An Esophageal Squamous Cell Carcinoma with Lymph Node Metastasis Presenting as a Small Subepithelial Tumor
}

\author{
Jang Won Park', Eun Jeong Gong ${ }^{2}$, Myeongsook Seo ${ }^{2}$, Baek Gyu Jun ${ }^{2}$, Hyun Il Seo ${ }^{2}$, Jong Kyu Park ${ }^{2}$, Koon Hee Han², Sang Jin Lee², \\ Young Don Kim², Woo Jin Jeong', Gab Jin Cheon ${ }^{2}$ \\ Department of Internal Medicine, Hanil General Hospital ${ }^{1}$, Seoul, Department of Internal Medicine, Gangneung Asan Hospital, University of \\ Ulsan College of Medicine $e^{2}$, Gangneung, Korea
}

\begin{abstract}
A subepithelial tumor-like esophageal carcinoma is rare. We report a case of an esophageal squamous cell carcinoma with lymph node metastasis presenting as a small subepithelial tumor. A 68-year-old man presented to our hospital complaining of hoarseness since last three months. Endoscopic examination revealed a $1 \mathrm{~cm}$ hard and fixed subepithelial tumor with surface erosion in the lower esophagus. A biopsy specimen was obtained using conventional forceps, and histopathological evaluation revealed few atypical squamous epithelial cells. Subsequent EUS demonstrated a homogeneous hypoechoic lesion in the deep mucosal layer. A CT scan of the chest showed a $3 \mathrm{~cm}$ mass in the right upper paratracheal area. EUS-guided fine needle biopsy of the lesion led to the diagnosis of squamous cell carcinoma with lymph node metastasis. (Korean J Helicobacter Up Gastrointest Res 2019;19:272-276)
\end{abstract}

Key Words: Endosonography; Esophageal neoplasms; Squamous cell carcinoma

\section{INTRODUCTION}

Esophageal cancer is associated with a poor prognosis and exceptionally a low survival rate. Although esophagectomy remains the standard treatment for localized esophageal cancer, there is considerable morbidity and mortality associated with surgery. ${ }^{1}$ Endoscopic resection has been widely used for the treatment of superficial esophageal squamous cell carcinomas based on favorable outcomes. ${ }^{2,3}$ Therefore, early detection and timely treatment are important to improve clinical outcomes of esophageal cancer.

Since esophageal cancers originate from the epithelial layer of the esophagus, most accompany mucosal abnormality. Therefore, endoscopic examination with biopsy is the gold standard for diagnosis of esophageal cancer. ${ }^{4}$ Advanced esophageal cancers usually present as a mass or ulceration, which can be easily recognized during endoscopic examination. Endoscopic diagnosis of superficial neoplasia can be challenging, as they appear as subtle and flat

Received: April 27, 2019 Revised: May 3, 2019 Accepted: May 13, 2019

Corresponding author: Eun Jeong Gong

Department of Internal Medicine, Gangneung Asan Hospital, University of Ulsan College

of Medicine, 38 Bangdong-gil, Sacheon-myeon, Gangneung 25440, Korea

Tel: +82-33-610-3106, Fax: +82-33-644-5495, E-mail: gongeun@gmail.com hyperemia or granular change of the esophageal mucosa. Nonetheless, esophageal cancer rarely grows in a subepithelial tumor (SET)-like pattern. Here, we report a case of esophageal squamous cell carcinoma with lymph node metastasis presenting as a small SET.

\section{CASE REPORT}

A 68-year-old man visited the otolaryngology department with complaints of hoarseness lasting since three months. He had been diagnosed and prescribed for high blood pressure. He was a never-smoker but had a history of habitual alcohol drinking for 50 years. He was otherwise in good health, with no history of gastrointestinal symptoms. Vital signs were stable and laboratory test results were unremarkable.

During laryngological examination, right vocal cord palsy was noted. The patient was referred to the department of gastroenterology for endoscopy. Endoscopic examination revealed a $1 \mathrm{~cm}$ hard and fixed esophageal SET with surface erosion $36 \mathrm{~cm}$ away from the upper incisors (Fig. 1). Forceps biopsy specimens were obtained from the mucosal lesion, and histopathological evaluation showed few atypical squamous epithelial cells. EUS using a $20 \mathrm{MHz}$ mini-probe

Copyright $\odot 2019$ Korean College of Helicobacter and Upper Gastrointestinal Research

(a) The Korean Journal of Helicobacter and Upper Gastrointestinal Research is an Open-Access Journal. All articles are distributed under the terms of the Creative Commons Attribution Non-Commercial License (http:// creativecommons.org/licenses/by-nc/4.0) which permits unrestricted non-commercial use, distribution, and reproduction in any medium, provided the original work is properly cited. 
demonstrated a circumscribed homogeneously hypoechoic lesion in the deep mucosal layer. Repeat biopsy with standard forceps was performed, which resulted in the diagnosis of squamous cell carcinoma.

Subsequently, imaging studies for staging were performed. CT scan of the chest and positron emission tomography revealed an approximately $3 \mathrm{~cm}$ mass in the right upper paratracheal area (Fig. 2). EUS-guided fine needle biopsy
(EUS-FNB) was performed (Fig. 3). The histopathological diagnosis was squamous cell carcinoma, and palliative chemoradiatiotherapy was adopted (Fig. 4).

\section{DISCUSSION}

SETs are usually encountered incidentally during endoscopic examination. ${ }^{5}$ The differential diagnosis of SETs in-
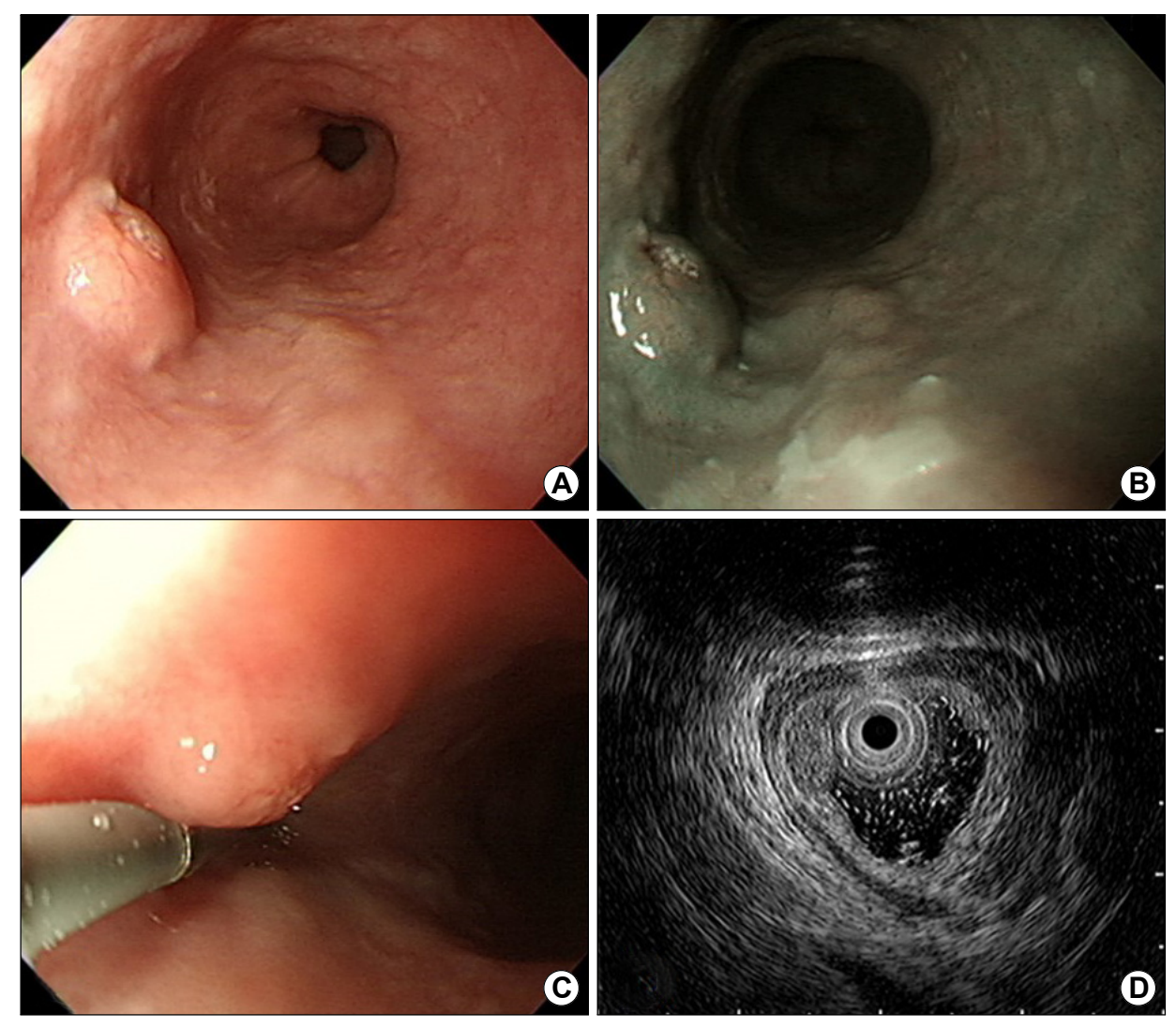

Fig. 1. (A, B) White light endoscopy and narrow-band imaging show a subepithelial lesion in the lower esophagus. There is erosion on the surface of the lesion. (C) The lesion is fixed and hard when pressed with forceps. (D) EUS show a homogeneous hypoechoic lesion in the deep mucosal layer.
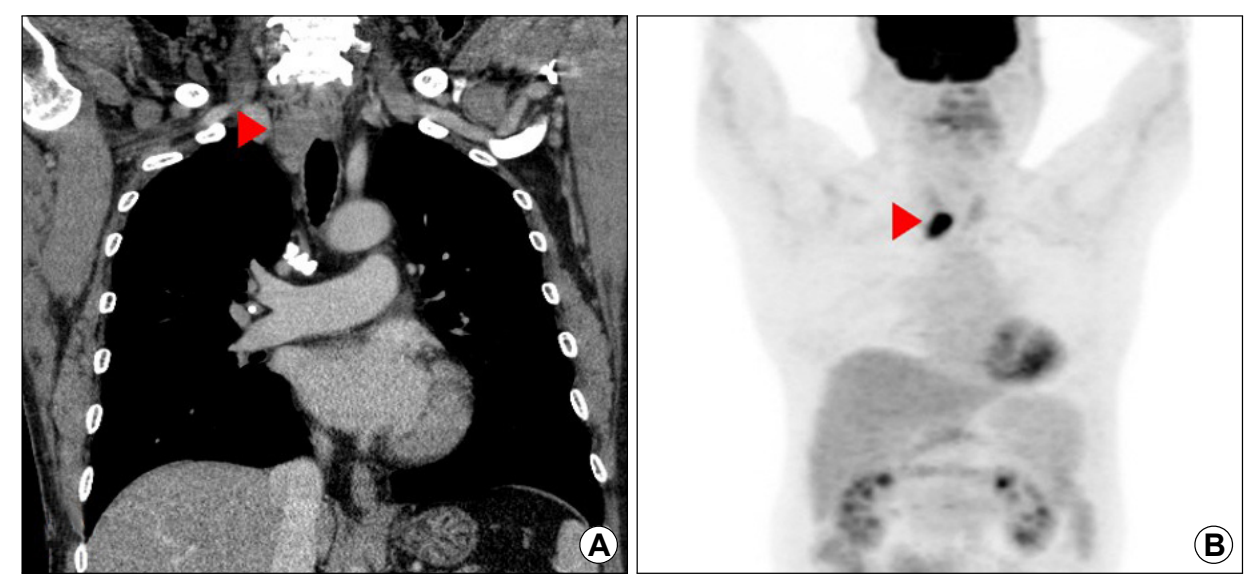

Fig. 2. (A) A CT scan show a $3 \mathrm{~cm}$ mass in the right upper paratracheal area (arrowhead). (B) A positron emission tomography scan of the corresponding lesion show hypermetabolic activity (arrowhead). 

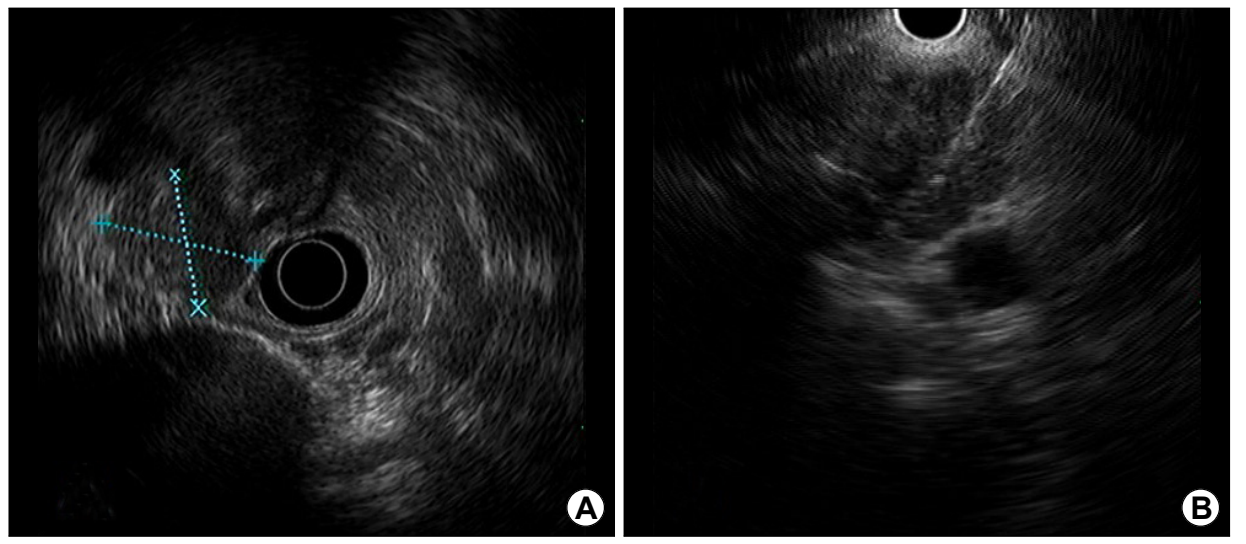

B
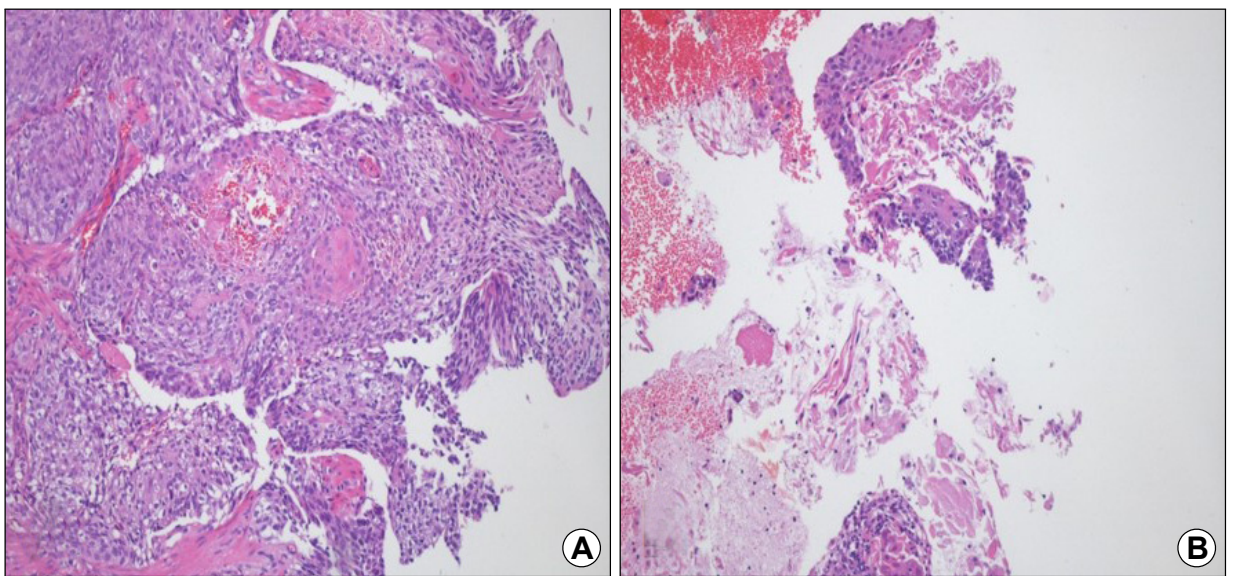

Fig. 3. (A) EUS shows a $25.4 \times 21.6 \mathrm{~mm}$ heterogeneous hypoechoic mass in the right upper paratracheal area. (B) A EUS-guided fine needle biopsy is performed. cludes both benign and malignant neoplasms, including leiomyoma, granular cell tumor, and gastrointestinal stromal tumor." ${ }^{6,7}$ Lymphoma or metastatic tumor can appear as SETs, and epithelial tumors rarely present SET-like appearance. ${ }^{8}$ They closely mimic the mesenchymal tumors on EUS, and carcinomas of SET-like growth may be of the poorly differentiated or undifferentiated type. ${ }^{8}$

SET-like pattern is a rare presentation of esophageal cancer. $^{9-13}$ In a previous study, the authors reported a case of advanced squamous cell carcinoma with multiple lymph node metastasis initially found as a $1 \mathrm{~cm}$ esophageal SET. ${ }^{10}$ Small surface erosion was observed on endoscopy; however, a biopsy specimen could not be taken because of poor cooperation of the patient. Endoscopic resection of the primary lesion was performed and subsequent surgery revealed advanced esophageal cancer infiltrated into the adventitial layer. In another case report, an approximately $0.8 \mathrm{~cm}$ esophageal SET was noted, and the presumed diagnosis was leiomyoma based on the endosonographic features. ${ }^{11}$ The final diagnosis was made after endoscopic resection of the tumor, which was esophageal squamous cell carcinoma invading the submucosal layer without lymph node metastasis. In these cases, the primary lesions were relatively small (less than $1 \mathrm{~cm}$ ) and they appeared as circumscribed hypoechoic lesion confined to mucosal and submucosal layers, suggesting the possibility of mesenchymal tumor. The diagnosis could not be made without clinical suspicion and endoscopic resection.

There have also been reports of intramural squamous cell carcinomas, which presented as esophageal SET with completely normal overlying mucosa. ${ }^{12,13}$ In these cases, the primary cancer was located mainly in the submucosa, and had initially been suspected of being SET. Endoscopy and radiological investigations could mislead to a diagnosis of SET rather than esophageal cancer due to the 
nonsuspicious appearance of the overlying mucosa.

Our case differs from those reported earlier because the endoscopic forceps biopsy was useful to make a definite diagnosis. During endoscopic examination, it is recommended to perform forceps biopsy on the mucosa overlying the SET. ${ }^{8,14}$ However, for most SETs, the results of standard forceps biopsy, in which tissues are obtained from across the epithelium that covers the tumor, are not diagnostic, even with large-capacity forceps or bite-on-bite technique; this is primarily because of its limited depth of penetration. ${ }^{15}$ In contrast, forceps biopsy may help reach a definitive diagnosis when there is a mucosal abnormality, such as surface erosion, changes to the vasculature, or ulceration. Therefore, meticulous evaluation and clinical suspicion are important. Image-enhanced endoscopy or chromoendoscopy with Lugol staining can be helpful for the detection and delineation of squamous cell neoplasm. In addition, repeated biopsy or endoscopic resection should be considered if malignancy is suspected.

EUS enables to characterize SETs, including the size, layer of origin, delineation, and echogenic pattern of the lesions. ${ }^{16}$ Current guidelines recommend that asymptomatic SETs smaller than $2 \mathrm{~cm}$ or having typical EUS features of benign disease can be periodically assessed. ${ }^{8,14}$ When SETs have clinically malignant features on endoscopy, such as irregular borders, ulceration, or growth during endoscopic follow-up, a histological diagnosis should be attempted to determine the optimal treatment strategy. Tumors confined to the mucosal and submucosa layers can be resected endoscopically. EUS-guided tissue sampling, such as EUS-guided fine needle aspiration (EUS-FNA) or EUS-FNB, provides adequate tissue samples for both histopathological and immunohistochemical analyses, particularly for those originated from the proper muscle layer. ${ }^{17}$ Several factors may contribute to the diagnostic performance of EUS-guided tissue acquisition, including the size and location of the lesion, needle size and type, sampling techniques, and utilization of on-site cytopathologist. ${ }^{18}$ In a previous report, which investigated the diagnostic accuracy of EUS-FNA in esophageal SETs, $47.7 \%$ of tissue samples were considered insufficient or nondiagnostic. ${ }^{6}$ In addition, the diagnostic yield of EUS-FNA was lower for small SETs less than $2 \mathrm{~cm}^{19}$ Every method of tissue acquisition has its limitation, and the choice of method for tissue diagnosis in SETs should be based on various factors.

In conclusion, an esophageal SET can be an atypical presentation of esophageal cancer, which should not be overlooked. Timely identification of this feature of the esophageal cancer is necessary for appropriate evaluation and management.

\section{CONFLICT OF INTEREST}

No potential conflict of interest relevant to this article was reported.

\section{ORCID}

\begin{tabular}{|c|c|}
\hline $\mathrm{rk}$ & \\
\hline & \\
\hline & \\
\hline & id.org/0000-0003- \\
\hline & $339-5031$ \\
\hline & (1) http \\
\hline & (D) https://o \\
\hline Jin Lee & (1) https://orcid.org/0000-0001-6297-7966 \\
\hline ig Don Kim & (1D https://orcid.org/0000-0001-9003-9862 \\
\hline & (1) https://orcid.org/0000-0001-7467-07 \\
\hline n Cheon & (1D) https://orcid.org/0000-0001-5937-5999 \\
\hline
\end{tabular}

\section{REFERENCES}

1. Low DE, Bodnar A. Update on clinical impact, documentation, and management of complications associated with esophagectomy. Thorac Surg Clin 2013;23:535-550.

2. Tachibana M, Hirahara N, Kinugasa S, Yoshimura $H$. Clinicopathologic features of superficial esophageal cancer: results of consecutive 100 patients. Ann Surg Oncol 2008;15: 104-116.

3. Park HC, Kim DH, Gong EJ, et al. Ten-year experience of esophageal endoscopic submucosal dissection of superficial esophageal neoplasms in a single center. Korean J Intern Med 2016; 31:1064-1072.

4. Barret M, Prat F. Diagnosis and treatment of superficial esophageal cancer. Ann Gastroenterol 2018;31:256-265.

5. Kim SG. Incidental gastrointestinal subepithelial mass. Korean J Gastroenterol 2010;56:341-345.

6. Baysal B, Masri OA, Eloubeidi MA, Senturk H. The role of EUS and EUS-guided FNA in the management of subepithelial le- 
sions of the esophagus: a large, single-center experience. Endosc Ultrasound 2017;6:308-316.

7. Codipilly DC, Fang H, Alexander JA, Katzka DA, Ravi K. Subepithelial esophageal tumors: a single-center review of resected and surveilled lesions. Gastrointest Endosc 2018;87: 370-377.

8. Nishida T, Kawai N, Yamaguchi S, Nishida Y. Submucosal tumors: comprehensive guide for the diagnosis and therapy of gastrointestinal submucosal tumors. Dig Endosc 2013;25:479-489.

9. Choi YY, Kim GH, Park DY. An incidental subepithelial mass in the esophagus. Lymphoepithelioma-like carcinoma appearing as a subepithelial tumor in the esophagus. Gastroenterology 2014;146:e1-e2.

10. Kim SY, Lee SK, Ryu HJ. Esophageal squamous cell carcinoma presenting as a subepithelial tumor. Korean J Helicobacter Up Gastrointest Res 2017;17:144-147.

11. Chuang CS, Lee IL, Lee KF, Tung SY, Wu CS. Diagnosis by endoscopic mucosal resection of a rare esophageal squamous cell carcinoma mimicking a subepithelial tumor. Endoscopy 2007;39 Suppl 1:E301-E302.

12. Kishino T, Yamaguchi Y, Yamagishi T, et al. Submucosal tumor (SMT)-like esophageal squamous cell carcinoma with gastric metastasis. Hepatogastroenterology 2000;47:1581-1584.

13. Sonthalia N, Jain SS, Surude RG, Pawar VB, Udgirkar S, Rathi PM.
Primary esophageal intramural squamous cell carcinoma masquerading as a submucosal tumor: a rare presentation of a common disease. Clin Med Insights Gastroenterol 2016;9:63-66.

14. Dumonceau JM, Deprez PH, Jenssen C, et al. Indications, results, and clinical impact of endoscopic ultrasound (EUS)-guided sampling in gastroenterology: European Society of Gastrointestinal Endoscopy (ESGE) clinical guideline - updated January 2017. Endoscopy 2017;49:695-714.

15. Ji JS, Lee BI, Choi KY, et al. Diagnostic yield of tissue sampling using a bite-on-bite technique for incidental subepithelial lesions. Korean J Intern Med 2009;24:101-105.

16. Gong EJ, Kim DH. Endoscopic ultrasonography in the diagnosis of gastric subepithelial lesions. Clin Endosc 2016;49:425-433.

17. Muniraj T, Aslanian HR. New developments in endoscopic ultrasound tissue acquisition. Gastrointest Endosc Clin N Am 2017;27:585-599.

18. Moon JS. Role of endoscopic ultrasonography in guiding treatment plans for upper gastrointestinal subepithelial tumors. Clin Endosc 2016;49:220-225.

19. Attila T, Aydin Ö. Lesion size determines diagnostic yield of EUS-FNA with onsite cytopathologic evaluation for upper gastrointestinal subepithelial lesions. Turk J Gastroenterol 2018; 29:436-441. 